\title{
ON READING HEGEL'S PHENOMENOLOGY OF SPIRIT
}

What does it mean to read Hegel's Phenomenology of Spirit? How is it to be read and to what end? What is at stake in this reading? What could be said about a text that, from the very beginning, puts the reader to the test at every point, challenging him to say what he means? The reader will be the site of the research. It is in his thought and experience that the concept will be demonstrated. The Phenomenology puts at stake for the reader nothing less than the truth of his own life. As phenomenology, the text tests itself against the reader's experience or rather initiates in him a performance in which he tests himself. Can he say what he means? Can he give voice to his experience? Does his claim to know the truth actually stand up when tested against his own experience?

In Hegel's philosophy the concept is produced neither by abstract argument nor by reason alone, but only through a phenomenology of experience that takes into account all the registers of life. The Phenomenology of Spirit ${ }^{1}$ provides a "ladder" to philosophical science insofar as the concept of logic must emerge first from the material conditions of life. Philosophy has

1. G. W. F. Hegel, Phenomenology of Spirit, trans. A. V. Miller (1807; New York: Oxford University Press, 1977). I have frequently altered Miller's translation to restore the clarity and consistency of Hegel's argument. I have also often used he/himself for it/itself in referring to a shape of selfconsciousness. In-text references cite paragraph numbers in the Miller translation. 
a duty to demonstrate to "natural consciousness" how the position of philosophical science already lies implicit in his experience $\left(\mathbf{g g}_{2} 6,29\right) .{ }^{2}$ The concept proves its truth through its power to organize and sustain forms of life. As the very infrastructure of experience, the concept can be discovered only through phenomenological analysis.

In the magisterial narrative of the Phenomenology of Spirit, the reader discovers a language adequate to unfold the transparency of the concept through all the regions and registers of life, from sensuous immediacy and the family, to science and politics, to art and religion. As the phenomenological interrogation unfolds, every identity proves to be an identity in difference, always already having given way to the two that is implicit within it $\left(\mathbf{g}_{18)}{ }^{3}\right.$ Any identity immediately sunders itself, so as to reveal that its truth lies in what first appeared to be its opposite. Through the phenomenological project of giving voice to experience or attempting to "say what we mean," the apparent opposite of each identity proves instead to be its essential other. The man of virtue, for example, might seem to be the opposite of the man of the world, who acts only in his own self-interest, but the former is not as good as he seems, nor the latter as bad. The man of virtue selfishly prizes his own moral purity above all else, while imposing his particular truth on everyone else. The man of the world, though he might seem to act for himself alone, actually benefits the whole: he creates a business and gives others employment or creates something transformational-the transcontinental railroad, the airplane, the iPhone, the Nike running shoe-that changes the way the community lives. Even the identity of the singleton ${ }^{4}$

2. I refer to the subject of Hegel's phenomenology with masculine pronouns out of philosophical necessity. Doing otherwise would constitute an egregious error in reading: as I will demonstrate, Hegel's philosophical subject is necessarily masculine. Writing as if one could simply insert sexual difference into Hegel's subject would obscure Hegel's insistence on the necessity to philosophy of the gender division of labor. Hegel takes women's experience and labor seriously as a distinct domain of human agency, but he means to efface that difference in an absolute 'I,' in a philosophical subject that is always already marked masculine. So, while it might be politically correct to employ 'he/she' or 'they' in referring to the subject of the phenomenological analysis, it would be philosophically incorrect, and, moreover, an erasure of Hegel's very attempt to erase sexual difference, letting Hegel off the hook on this issue.

3. Entzweiten, or "two-ing," occurs throughout the text. In ordinary German, entzweigehen means "to come apart" or "to break in two." Etwas entzwei schneiden is to cut something in half. The opposition comprising identity is a belonging together, as one half belongs to the other.

4. "Singleton" translates der Einzelne. Miller's translation, "individual," obscures the crucial distinction of this term from das Individuum, the "individualized" singleton who has learned that he is only a member of a whole. "Singleton" avoids the paleonymic effects of the terms subject or human being, while emphasizing the "self-standing" (Selbstständigkeit) of self-consciousness. Philosophy must appropriate this "immediate self-certainty" in which the self-conscious singleton 
himself proves to be an "incommensurable" difference between a changing determinate self and an 'I' that persists as the same through the flux of becoming. ${ }^{5}$

The truth of phenomenology, then, would seem to be the irreducibility of difference and the inability of the concept to master the proliferation of differences in life. The method of interrogation that yields the transparency of the concept seems to describe an infinite movement of becoming that could never terminate in an absolute identity to which nothing is other, that could never be fully anticipated in any concept, as physical events are known in advance in the laws of physics. As a phenomenologist, Hegel seems to subscribe to the novelist's epistemology: only the impression is a guarantor of truth. The truths of the abstract intellect may be logically coherent, but there is no guarantee that they are about anything real. They are "less profound, less necessary" than the truths that "life communicates to us against our will in an impression which is material because it enters us through the senses but yet has spirit which is possible for us to extract." As a phenomenologist, Hegel not only insists on the singular singleton as the site of the realization of the self-conscious concept, he also insists that the concept cannot be thought apart from its materialization. The truth is not only the "result" but also "the process by which it came about" $\left(\mathbf{g}_{3}\right)$. The concept will always be marked by its emergence from life and can only be realized in the singleton's thought. While the concept must be thought as distinct from the self-conscious singleton, as surpassing the singularity of his experience, this proves to be a "distinction which is no distinction," as there is no other "medium" for the concept but that experience. ${ }^{7}$ Thus, just as phenomenology discovers the living singleton to be

knows himself as existing on his own. In so doing, phenomenology demonstrates that the singleton is in truth only a member of multiple communities, only a "moment" in the tides of generations across which the whole of spirit is realized. The movement of identity, sundering itself and discovering itself in relation to its other, unfolds the whole of human history and culture. The movement, not the moment, proves to be the truth of spirit.

5. See 9705: "Incommensurability" is the "essential nature" of the "organic." The metaphor of the organism controls the text. The development of the concept is "organic," as the "bud disappears in the bursting-forth of the blossom" ( 2 ). The individual comes forth from the singleton, as the man from the boy. Spirit emerges out of material life, as the oak from the acorn ( 13$)$.

6. Marcel Proust, In Search of Lost Time, vol. 6, trans. C. K. Scott Moncrieff and Terence Kilmartin (1927; New York: Modern Library, 1983), 273.

7. This phrase "distinction which is no distinction" occurs throughout Hegel's text. See 9166, where the difference between knowing and being is in question-a difference that, as phenomenology reveals, "falls within consciousness." 
an "incommensurable difference," so too the interrogation reveals an incommensurable difference between language and experience, between philosophical narrative and life, between the abstract concept and its material realization. Philosophy, as phenomenology, reveals a concept that is always marked by this difference and, thus, always wears a singular face.

At the same time, Hegel's phenomenological analysis aims at "that point at which knowledge need no longer go beyond itself because nothing is other to it" ( 80 ). Phenomenology will prove to be only a propaedeutic to logic and to an encyclopedic project meant to exhaust the field of knowledge. The Phenomenology sets as its goal an absolute knowing in which all difference has been surpassed and comprehended, so that nothing is "left behind." Nothing is "other" to absolute knowing: it is the exceptional identity in which all difference is at once articulated and reduced. All the possible shapes or forms of human experience will have been taken up in it and accorded, each one, its proper place as a moment in a completed system of shapes. Absolute knowing may be manifest only in the self-conscious singleton, but in its master narrative, his very singularity has been reduced to a mere passing moment, surpassed in a thought that belongs to each and all. ${ }^{9}$ With the arrival of absolute knowing, the singleton "must expect less for himself and less must be expected of him" ( $\mathbf{9} 72)$.

Absolute knowing only comes on the scene at the "time that is ripe to receive it," at that moment in human history when all the possible shapes and forms of life have already been articulated in experience and stand ready to be reflected in thought $\left(\mathbf{g}_{71}\right)$. The appearance of absolute knowing marks the "end of history" and the "end of art" insofar as it reflects the completed system of shapes that comprise human experience. There will be more history and more art; but these domains are no longer philosophically interesting, as they can offer no novelty. They can yield only a repetition of the essential forms already reflected in the completed whole of absolute knowing. In absolute knowing, the concept is "grasped," so as to "annul" (tilgen) time itself ( $\mathbf{9 0 1}$ ). Absolute knowing inaugurates the project of logic, where

8. As I will discuss in chapter 4 , in the installation of the gender division of labor as necessary to the life of spirit, the sister is "left behind" ( 458$)$.

9. As Hobbes remarks, "all men by nature reason alike." Thomas Hobbes, Leviathan (1651; Cambridge: Cambridge University Press, 1991), chapter 5, פ16. 
the concept is to be thought as such, apart from its materialization and in its "pure" conceptuality.

Hegel, then, writes with both hands. On the one hand, he insists on the materiality of the concept as an infrastructure of life, on the singleton as the site of its realization, and on the ineluctable sundering of any identity into the two that constitutes it. On the other hand, he aims at the purified concept of a science of logic beyond phenomenology, the science of experience. He aims at a thinking in which singularity has been erased, and he means to install an identity in which difference has been comprehended "so that nothing is other to it." The phenomenological interrogation will master any difference that appears by incorporating it into a system of differences thought as one. The one returns to itself in the many, mastering difference, and leaving nothing unsaid or unthought.

This double writing requires a double reading.

Reading with Hegel, the reader will discover in the phenomenological interrogation how identity and difference, the movement of self-sundering and return from otherness, operate across the registers of life, how this movement is reflected in nature, the body, the family, and Earth, at the same time that it produces natural science, politics, and philosophy itself. In this capacious narrative, the singularity and novelty of materiality mark the emerging concept. Identity belongs to a movement of differentiation that creates knowledges, solidarities, and cultures. And the truth of experience lies in this becoming. On this reading, philosophy must be phenomenology, for only the interrogative method can capture the specificity of the concept as it emerges from the movement of becoming.

Reading against Hegel, the reader will discover that Hegel's attempt to complete the phenomenological project, leaving it behind for logic and a "purified" concept, comes undone at three points. Three dangling threads refuse to be woven into the completed fabric of absolute knowing. Sexual difference, the mortality of the singleton (which differentiates him as this one and not the others), and the differences of style in art and literature each resist Hegel's attempt to knit them up. Perhaps, these differences entangle the writing hands so that the seams of absolute knowing cannot be sewn closed and remain indefinitely unfinished. Perhaps, the attempt to "purify" the concept and "pulverize" singularity remains tangled in the threads of these recalcitrant differences. 


\section{SEXUAL DIFFERENCE}

Hegel's account of sexual difference unfolds in his interpretation of the figure of Antigone and his analysis of the relation between family and state. The gender division of labor is necessary, Hegel argues, for two reasons. First, it is practically required, because only if women tend the body will men be free for the discursive pursuits of science, politics, and philosophy. Without this assignment of the care of the body to women, the community will have no way to feed itself, to raise its children, and to care for the sick and aged. ${ }^{10}$

Second, it is philosophically required. Unlike other philosophers of the tradition who render woman a man without reason ${ }^{11}$ or an emotional supplement to man's rationality, ${ }^{12}$ Hegel accords to women's experience an essential place in the phenomenology of spirit, as the embodiment of the ethical and the guardian of the body. Her distinctive experience cannot be reduced to man's, and it is just as essential as his to the life of the community.

Only her assignment to the care of the body and her exclusion from the discursive pursuit of philosophy prevent this irreducible difference from undermining the aim of absolute knowing. She is to be "left behind" in the family, so that her difference may not mark the master narrative ( 458$)$. On the one hand, her difference is absolutely essential to the selfrealization of spirit; on the other, this difference must be effaced if selfconsciousness is to reach "absolute knowing," in which "knowledge need no longer go beyond itself because nothing is other to it." Existing as this

10. Hegel has a point here. When women leave the home for public life, there is no one left in the domain of the family to care for the needs of the body. The community is undermined by social problems: latch-key children, elders in nursing "homes" because there is no longer a daughter available to take care of them, or an obesity epidemic because processed or fast foods have replaced home-cooking. I certainly would not argue for maintaining the gender division of labor, but Hegel's point that some infrastructure is necessary to negotiate the claims of family and public life cannot be denied. The challenge for feminism and the political community is to create new infrastructures, other than the gender division of labor, that are capable of sustaining the claims of both family and public life, both the body and thought.

11. Hobbes frequently groups women, children, and "savages" as a single class, identified by their incapacity for rational thought.

12. For Rousseau, woman's purpose, to which her education should be directed, is to soften man's temper and supplement his rational judgments with compassion. See Jean-Jacques Rousseau, Emile: Or, On Education, trans. Allan Bloom (1762; New York: Basic, 1979). 
aporia, she remains the "eternal irony of the community," an irony that remains unresolved in absolute knowing (475).

\section{THE MORTALITY OF THE SINGLETON}

Hegel insists that the singleton "comes into existence as such" only through the "force [Kraft] of speech" ( 508$)$. Self-consciousness exists only in language, as a transcended self. Thus, substance is "humiliated" (erniedrigt) and the immediacy of experience rendered a "vanishing moment" (5532). Only language can embody the identity of the pure universal 'I' with the particularity of the singleton in the flux of becoming. ${ }^{13}$ Just as in the interrogation of sensuous immediacy the 'now' preserves itself as the form of experience through the negation of determinate 'nows,' so, too, the pure 'I' of language and the concept maintains itself through the negation of the determinate contents that distinguish the singleton as this one.

The logic of appearance - the "arising and passing away that never arises or passes away"-turns out to be the truth of self-consciousness, who exists only as this "vanishing" (47). Hegel means to leave behind the substance of the singleton by transforming him into a linguistic being, who exists only as something conceptual or as thought. Hegel's terrestrial faith, his belief in the immortality of Earth, the "eternal individual," sustains his belief in the immortality of appearance and the genus life (452). The mortality of the singleton does not trouble this faith, for if "the universal is only actual in the singleton," the eternal tide of generations will always assure its realization despite the death of the singleton. The truth of the singleton is to be the site of this complex process of mediation through language; thus, the universal is actualized in such a way as to transcend the specificity and mortality of each and all. What persists is the logic of mediation, and the death of the singleton leaves no trace.

Perhaps the singleton and his mortality can no more be left behind than the sister can. Hegel's own method stipulates that nothing can be left

13. As Derrida remarks, "my-death" is structurally necessary to pronouncing "I am." For the speaker's utterance to make sense, he must be subject to a phenomenon of displacement, whereby another speaker could come to take his place and make the utterance his own. Jacques Derrida, Speech and Phenomena, trans. David B. Allison (1967; Evanston, IL: Northwestern University Press, 1973), 96. 
behind, unarticulated in the 'I' that produces the conceptual narrative, but, perhaps, the irreducible specificity of mortal life-for the reality of death is always $m y$ death and never an abstraction-resists and always exceeds the grasp of the concept. ${ }^{14}$

Hegel can claim the closure of the phenomenological project in "that point at which knowledge need no longer go beyond itself because nothing is other to it" only through violent acts of erasure. Woman and the mortal singleton have each already been erased. Hegel completes this effacement of specificity through the erasure of the irreducibility of the signature in art. These erasures not only violate the phenomenological method; they leave a trace and give to the universal a singular face.

\section{ART/LITERATURE}

Plato's theory of art is his philosophy, and since philosophy down the ages has consisted in placing codicils to the platonic testament, philosophy itself may just be the disenfranchisement of art.

At least since Plato, who calls this "old quarrel" an "ancient enmity," philosophers have found it necessary to subjugate art in order to establish the sovereignty of philosophy as the discipline of truth. ${ }^{15}$ What is at stake here is nothing less than philosophy's aim of an absolute knowing freed from the finite perspective. The irreducible differences of style in literature and art undermine the pretensions of philosophy to offer a master narrative beyond finite difference. Art portrays the shattering of the one world into the aspects of the finite perspective, its multiplicities and differences. Art promises no absolute vision of the truth beyond the world of appearances, in which these differences would be comprehended and effaced. Thus, the

\footnotetext{
14. "The syllogism 'Caius is a man, men are mortal, therefore Caius is mortal' had always seemed to him correct as applied to Caius, but certainly not as applied to himself. That Caius-man in the abstract-was mortal, was perfectly correct, but he was not Caius, not an abstract man, but a creature quite, quite separate from all others. . .'Caius really was mortal, and it was right for him to die; but for me, little Vanya, Ivan Ilych, with all my thoughts and emotions, it's altogether a different matter. It cannot be that I ought to die. That would be too terrible.' " Leo Tolstoy, The Death of Ivan Ilych, trans. Rosemary Edmonds (1886; New York: Signet Classics, 1960), 131-32. Death may be universal, but it always wears a singular face.

15. Republic, lines 598-99. See also Phaedrus, lines 275-76.
} 
pretension of art to express truth undermines the aim of a knowing "that need no longer go beyond itself because nothing is other to it." While religion and philosophy aim to think the whole of reality at one go in a master narrative, the artist strives to embody in his work only a distinctive style or way of seeing. Thus, the history of philosophy is, as Danto remarks, "a cosmic labyrinth designed to keep art, like a minotaur [a monstrous being], in logical quarantine." ${ }^{16}$ Philosophy, to maintain its concept of truth, must be protected from the problem of style.

Hegel takes an approach to art that reduces the work to a symptom of culture, or the "embodiment" of the spirit of a "free people" ( 9700$)$. A work of art is a conscious production "made by human hands." However, in creating his work, the artist has "depersonalized" himself: "to himself as a particular singleton he gave in his work no actual existence" (9708). The work, Hegel claims, represents a worldview or form of life, rather than the differentiating style of the artist. ${ }^{17}$

Here, and in his Aesthetics too, Hegel reduces the work to an instance of a general form. Works are subsumed under the general categories of the symbolic, the classical, and the romantic. A hierarchy of arts is established, in which the self-conscious linguistic art of literature surpasses the unconscious, inarticulate spirit of the plastic arts of sculpture and painting. Beyond a few references to the genius of Homer, Sophocles, Shakespeare, and Raphael, Hegel offers no sustained analyses of specific works of art on their own terms. ${ }^{18}$

In claiming for philosophy an absolute knowing, Hegel attempts to erase or leave behind the specificity of its conditions of emergence and the specificity of its narrative, thereby violating his own admonition that the truth is not the result alone but the result and the process by which it came

16. Arthur Danto, "Philosophizing Literature," in The Philosophical Disenfranchisement of Art (New York: Columbia University Press, 1986), 165-66.

17. Many contemporary philosophers follow Hegel's approach. In Les Mots et les choses (Paris: Gallimard, 1966), Foucault analyzes Velázquez's Las Meninas as a depiction of the logic of classicism without saying anything about its sensuous qualities. Similarly, Starobinski comments on David's Oath of the Horatii as an emblem of revolutionary fervor rather than a visual experience. Jean Starobinski, 1789: The Emblems of Reason, trans. Barbara Bray (1973; Charlottesville: University of Virginia Press, 1982).

18. Despite the importance of the figure of Antigone to his argument, Hegel gives no sustained analysis of the trilogy of Sophocles's Theban plays. He ignores Oedipus at Colonus altogether, as so many feminist commentators do, and, like them, he misses the role of Ismene in advancing the very virtues that in his own analysis prove essential to community: Ismene's generosity, solidarity, and forgiveness against the hardheadedness and hardheartedness of Oedipus, Antigone, and Creon. 
about (13). Hegel attempts to write as if he were style-less or the zero degree of style, as if he could erase his own authorship and leave behind a book that was nothing but the anonymous self-articulation of spirit.

A genuine phenomenology of aesthetic experience, however, discovers joy and truth precisely in the differences between Vermeer and Rembrandt, Mozart and Beethoven, differences that cannot be subsumed in or predicted by any general form, which the signatures always exceed. Each name presents not only an easily recognizable style, but also a specific universal. Each name unfolds the whole of a world in a distinct way that proves its universality by creating for itself a community of adherents. Style exhibits the unity and wholeness that Hegel accorded to absolute knowing, but in a universe of differentiated styles of experience. Hegel thought he would articulate the truth; the artist, less grandiose and bound to the specificity of sensuous life, only claims a place in a universe of styles, each one an access to truth. As Proust argues,

Thanks to art, instead of seeing one world only, our own, we see that world multiply itself and we have at our disposal as many worlds as there are original artists, worlds more different one from the other than those which revolve in infinite space, worlds which, centuries after the extinction of the fire from which their light first emanated, whether it is called Rembrandt or Vermeer, send us still each one its special radiance. ${ }^{19}$

The differences of style in art make accessible individual difference as something universal, as a specific difference or perspective from which the whole of the world unfolds. Art teaches us that, contrary to philosophy's pretensions to an absolute knowing, to a master narrative, all is not to be thought at one go. It gives access to the novel difference of the other, who cannot be reduced to the same. Far from betraying substance, as Hegel claims, literature betrays instead the empty pretension of the philosopher to have found the narrative of the one, as if he could touch the horizon of the sky with his hand. Hegel's own phenomenological analysis, his own insistence on the concreteness of the concept as a material infrastructure of 
life, will undermine the legitimacy of the project of logic, where the concept would be thought not in its specificity but in general or as such.

Hegel demonstrates that the essence of being is "two-ing" (Entzweiten). Any unity immediately sunders itself into its constituent moments. Hegel's own attempt to install absolute knowing, the one truth or master narrative, will always be undone by the sister and the irreducible two of sexual difference. It will always be forestalled by the reality of the mortal singleton, by the ineradicable difference between his determinate being and the pure 'I' of language. And it will always be deferred indefinitely by the incommensurable differences of style in art and literature, which cannot be subsumed by a cultural form or erased in a general concept.

Hegel's move to logic founders on his fidelity to the phenomenological evidence: while aiming at the installation of a purified ' $I$ ' that exists only conceptually in language, he continues to insist on the material difference of the singleton as a necessary and ineffaceable moment. His own logic requires that he maintain this incommensurate difference as irreducible, rather than resolve it in a purified 'I.' Against his own phenomenological analysis and his demonstration of the concept as a material infrastructure of life, Hegel works the themes of "purifying" the concept and "pulverizing" singularity, as he works toward the claim of an absolute voice. $\mathrm{He}$ employs the most violent language in his attempt to "pulverize" the singleton (364) and to "humiliate" and "betray" substance (9532, 732). He attempts to tear the concept away from its adherence to the sensuous, but this would produce only the sort of empty abstraction that he himself decries. Perhaps, adherence to the phenomenological method and the materiality of the concept will undermine forever the philosopher's attempt to touch the sky with his hand.

Reading the Phenomenology of Spirit, pay attention to what is left behind in a narrative that claims to articulate the whole of experience. Pay attention to the erasures of difference that eviscerate the "two-ing," which is synonymous with life for Hegel. Pay attention to the price to be paid if phenomenology itself is to be left behind. 
